by the Inland Revenue authorities of the Crown properties transferred from the Office of Woods to the Forestry Commission. The chief of these were the New Forest and the Forest of Dean, the total valuation of which amounts to $£ 1,227,495$.

Under education and research the Report sum- marises the conclusions of the Irvine Committee on the training of candidates for Government forest services. The Commissioners pass no comment upon these conclusions which, it is understood, are receiving the careful consideration of the universities concerned.

\title{
Harvey and Preventive Medicine
}

A BRIEF account of Sir George Newman's Harveian Oration to the Royal College of Physicians of London appeared in NatuRE shortly after its delivery (NATURE, Oct. 29, p. 657). The full text of the discourse has since been published in pamphlet form.*

In his discussion of the new physiology which was inaugurated by Harvey's demonstration of the mechanism of the circulation of the blood, Sir George Newman points out that in 1622, six years after Harvey's first Lumleian discourse and six before his book was published, the demonstration of the lacteals and lymphatic system by which nutriment reached the blood was made by Aselli, Pecquet and Rudbeck. In 1648 the chemistry of digestion and the blood was investigated by van Helmont. Ten years later, the corpuscles of the blood were discovered by Swammerdam and Malpighi, and in 1661 Malpighi revealed the existence of the capillaries, which had been suspected by Harvey who, in the absence of a microscope, had been unable to detect them. In 1669 the contributions to the physiology of respiration by Boyle, Hooke, Mayow and Richard Lower demonstrated the purpose and process of aeration of the blood in the lungs, its selective use of the oxygen in the air, its conveyance to the tissues by the blood, and the resulting vitality and functioning of the tissues.

In the succeeding century, the actual gases which control life - carbonic acid, nitrogen and oxygen-were separated and fresh knowledge of the nervous and digestive systems was acquired. In the middle of the nineteenth century the foundations of endocrinology were established by the work of Thomas Addison, Claude Bernard and Brown-Séquard, and since then the progress of physiology in Great Britain has been pre-eminent in quantity, quality and scope.

Sir George Newman next considers the application of these discoveries to preventive medicine. He points out that from the sixteenth century onwards, the research worker has collaborated with the private practitioner and the public medical officer in the prolongation of life and the prevention of disease.

* "The Debt of Preventive Medicine to Harvey and the College of Physicians." (Harveian Oration, 1932: The Royal College of Physicians of London.) By Sir George Newman. Pp. 47. (The British Periodicals Ltd., 19 Cursitor Street, E.C.4.) 1s. net.
Striking examples of this statement are furnished in the eighteenth century by Lind and Sir Gilbert Blane in their defence of the health and the dietary of seamen, by William Cadogan, the pioneer in maternal and child welfare, and Sir John Pringle, who reformed the health of the Army. In recent times the labours of modern physiologists have con. tributed not only to the conservation of health but also to the prevention and cure of disease, as is exemplified by their work in connexion with cretinism, goitre, diabetes, anæmia, malnutrition, deficiency diseases, beri-beri, osteomalacia, scurvy and rickets.

The study of the cause and control of infective diseases is taken by Sir George Newman as another example of the Harveian method and spirit. The conveyance of infection by the circulating blood was acknowledged by Harvey's contemporaries, such as Glisson and Sydenham in the seventeenth century, and by the eighteenth century physicians who explored the circumstances and clinical features of infective diseases and observed their relation to external environment, to seasons and to meteorological conditions. Examples of such men were Huxham, who investigated typhoid, typhus, Devonshire colic, scurvy and scarlet fever; Heberden, who studied chicken-pox, measles and epidemic colds; Fothergill, who described epidemic sore throat; Haygarth, well known for his work on small-pox and typhus ; Edward Jenner, who introduced vaccination, and Willan, the father of British dermatology. It is noteworthy that in spite of the absence of any exact knowledge of the causation of disease, which was not reached until the advent of bacteriology in the later half of the nineteenth century, two significant conquests were achieved by the English before the end of the eighteenth century in the control of scurvy and of small-pox.

The production of artificial immunity, which Sir George Newman rightly regards as the greatest single advance in preventive medicine, is chosen by him as yet another example of the application of the Harveian method. Although the protective qualities of the blood were known to Harvey, it is only within comparatively recent times that an explanation of this property has been found, thanks to the work of Pasteur, Lister, Metchnikoff and Sir Almroth Wright.

\section{Spreading of Liquids on Solid Surfaces}

$\mathrm{I}^{\mathrm{T}}$ is generally supposed that on metals as well as on water the fatty oils and fatty acids should possess a more pronounced spreading tendency than the mineral oils, yet experiments show that this is not the case. Buckley and Snyder (J.Amer. Chem. Soc., Jan.) have confirmed this observation and have discovered an interesting phenomenon of rupture of thin layers of liquid on a solid surface due to the instability created by an underlying adsorbed film of low surface energy. Fatty oils and fatty acids lower the static coefficient of friction between metal surfaces more than do mineral oils of the same viscosity, and a mineral oil containing a small percentage of a fatty acid lowers the friction almost as much as a pure fatty oil. This is in agreement with a preferential adsorption of fatty acid on the metal surface, indicating that these acids lower the surface tensions of metals more than do mineral oils.

Mineral oils which spread rapidly on ordinary metal surfaces seem to have no spreading tendency on a metal surface covered with an invisible fatty acid film. When a drop of petroleum oil containing 